This is an Accepted Manuscript of an article published by Taylor \& Francis in International Journal for Academic Developmenton 7/6/2016, available online: http://www.tandfonline.com/10.1080/1360144X.2016.1188819. http:// authorservices.taylorandfrancis.com/sharing-your-work/ (Publisher journal website 12/9/2017)

\title{
The place of trust in Continuing Professional Learning programmes: supporting authentic reflection in portfolio assessment
}

\author{
Dr. Claire Stocks (University of Manchester) and Dr. Chris Trevitt (The Australian National University)
}

\begin{abstract}
:
This paper considers why academic participants on Continuing Professional Learning (CPL) programmes often struggle with the demands of practice-based learning, and why they can find the reflective portfolio particularly challenging. We argue that convenors and participants can benefit from differentiating between 'academic learning' and 'learning in academia' (to practice as an academic). In a higher education environment where trust has been increasingly replaced by the monitoring and measuring of performance, CPL participants can find themselves on unfamiliar learning territory which is not conducive to risk-taking. For participants to have the chance to fully engage with CPL opportunities, trust (in CPL convenors and tutors, in the CPL process and in the portfolio as a useful reflective tool) must be established. We identify how convenors can build the level of trust required for participants to offer an authentically reflective portfolio account of their practice. By making explicit (to themselves, to senior management, to course participants, to tutor and assessor colleagues) the way that trust and trust-building underpins CPL, course convenors can support the processes of authentic portfolio development and assessment.
\end{abstract}

Keywords: Continual Professional Learning (CPL); trust; reflection; portfolio; assessment; teaching development

"Learning is so driven by assessment that the form and nature of assessment often
swamps the effect of any other aspect of the curriculum"

Boud $(1990,103)$

"...learning-enhancing forms of assessment have not been commonplace in education". Kvale $(2007,62)$

"...accountability may represent a threat to trust and it may lead to defensive assessment practices."

(Carless, 2009, 82

Our interest in the role played by trust and portfolio assessment in Continuing Professional Learning (CPL) programmes arises from our experiences as convenors of such programmes. In an earlier paper, we have made clear that we prefer the term 'continual professional learning' (CPL), since it avoids the deficiency connotation often associated with the word 'development' (Trevitt and Stocks, 2012, 245). Before writing this paper we had each supported our colleagues to compile, and acted as assessors on, upwards of 50 portfolios, over several years, in two different countries. In the UK, one of us mainly worked with very novice teachers (generally PhD candidates or early career researchers), while in Australia, the other worked with a broader range of academic staff. Like Carless, our interest in trust as it relates to assessment of CPL programmes is not so much with the "reliability of judgements" and "whether grades can be trusted" as with the "interpersonal dimensions to trust or distrust" and "the confidence one has in the likelihood of others (management, administration, colleagues, students) acting responsibly" (Carless, $2009,81)$. Academic developers are often keenly aware of the need to establish both credibility and trust with academic colleagues if their work is to be successful. Trevitt (2008) explains that one component of his 'cognitive apprenticeship' approach to an action research project with medical school participants involved a "Sustained (12 weeks or more) trickle feed conversation used to build trust" (499), and in another paper he reports a colleague's realisation that to effectively input into the development of a law course, "It was crucial to establish trust at the outset [...] The mutual trust and established rapport provided a level of comfort from which the conversation could develop" (66-7). Our specific interest in the need for trust in development work has arisen during our experiences working with colleagues when 
compiling portfolios: that is, when portfolios have been used to do "double duty" (Boud, 2000, 159) employed in service of both learning and assessment (Trevitt and Stocks, 2011; Trevitt, Stocks and Quinlan, 2012), a situation increasingly of interest as pressures for teaching development in academia intensify.

In our roles, we have endeavoured to not only model good assessment practice, but also to use assessment to support the kind of learning that we value. Participants are early career academics primarily focussed on learning to teach and, to judge from one recent high level report, such programmes may be about to become much more ubiquitous, at least in Europe (HLGMHE, 2013). In common with many other UK (as well as overseas) university teaching development programmes, the reflective portfolio is a primary form of assessment. In this paper we consider why participants often struggle with this approach to assessment, how to foster engagement in the authentic ' reflection that underpins effective CPL and, specifically, the role that trust -in various guises - plays in supporting these aims. Trust building, we claim, lies at the heart of the prolonged period of formative engagement that culminates in a successful portfolio.

\section{Why do academics struggle with reflective portfolios?}

Recently, David James has drawn attention to what he terms a 'learning cultures' perspective on assessment practice, which he contrasts with alternative perspectives such as 'technical' -focussing on issues like reliability, validity, efficiency and accountability - or 'interactionist' - emphasising the human agents involved in the assessment process. For James, this perspective highlights the "social practices through which people learn" and "how different learning cultures enable or disable different learning possibilities" $(2014,160)$. This accords with our experiences of the challenges experienced by colleagues working with portfolios and the questions they raise about the dominant values, attitudes and approaches in their everyday practice. In order to support participants to engage in an authentic interrogation of their context and practice, CPL convenors have to be aware that a major part of their role is to build participants' trust in themselves, the course as a whole and in the assessment in particular (since, in practice, assessment drives learning - Boud, 1990). It is useful here to distinguish between 'trust' and 'trustworthiness' since, as Kharouf, Sekhon and Roy argue, "trust is the student's psychological state, while trustworthiness is a characteristic of the [course/assessment/convenor]" $(2014,3)$. Trustworthiness is something that can be demonstrated and cultivated, and is usually "acquired after a series of interactions" (Kharouf et. al., 2014, 3). This distinction is useful since it reminds us that participants' trust has to be built - something that generally requires thoughtfulness and commitment sustained over time. Demonstrations of trustworthiness lead to "a belief that the other party will only perform actions which result in positive outcomes for both parties" and create an environment where participants are more likely to engage in authentic reflection (Kharouf et. al., 2014, 3).

One participant's perspective on the anxieties that portfolio assessment can raise comes from Mary Anne FitzPatrick and Dorothy Spiller $(2010,175)$ :

I felt ashamed somehow that I had been ambushed by this task - which should have been reasonably straightforward - an account of my teaching, its philosophy and practice. We were given examples of portfolios written by previous students. Many of these exemplars came from men, some of whom were senior academics and teachers who had been teaching for a long time and were recognised as experts in their academic fields. Their portfolios were exemplary. And it quickly became obvious that my portfolio was not going to shape up into anything like theirs, because of some fundamental differences between us - I am a woman and I had been teaching full-time for two years. I felt unsettled by what seemed to be a common tone to their portfolios - a certain self-promoting, congratulatory first person voice that left me uncomfortable and embarrassed on behalf of these authors. Their portfolios were clean, wellstructured records of achievements way beyond my experiences of tertiary teaching.

This account raises several issues not least to do with the role of trust (and trustworthiness) in negotiating portfolio expectations. Like many academics, this participant is unfamiliar with the portfolio format and, consequently lacks confidence in her ability to deliver what is apparently expected. For people who have previously succeeded in academia this can be a daunting position to find themselves in, and it is understandable that participants can become anxious and overly focussed on the assessment product rather than the learning process. 
Like many of our CPL participants, the speaker above is also an early-career academic, one who lacks the experience and confidence of established colleagues whose portfolios are offered as exemplars (with their self-confident and 'congratulatory' tone these so-called 'exemplars' are not, incidentally, what we would necessarily consider to be model portfolios). Our early-career participants are not only at a crucial stage of getting to grips with their new role and identity as an academic staff member, but are also often juggling competing demands on their time and attention. They are also in the process of trying to understand what professional learning is, and how it might benefit them in the longer term. The fragility of their new academic identity is exacerbated not only because they are often still on probation when they take our programmes, but because successful completion is integral to the probation process. Furthermore, they can lack the political power and support networks of more established colleagues, all of which are likely to contribute to the sort of situation epitomised by the speaker above; she is completely unable to relate to self-assured 'records of achievements'.

In contrast to the account of alienation above, some of the feedback offered on one of our programmes, and reported in Trevitt et. al (2014), suggests that participants valued the support and security that the cohort offered. One participant, in particular, explained "I appreciated being in a group with others whose concerns and situations were similar to mine [...] It was a safe environment for bringing up problems and dealing with difficult situations" (emphasis mine, 2014, 71). Here we see the important role that trust plays in creating a culture where participants feel able to make (semi)public the problems and challenges that they face. Conversely, in a personal e-mail communication between one course participant and Trevitt, the participant states,

I am well aware that what I have done is 'hide' some of the more abstract concepts that I am grappling with and focused on the more concrete aspects of my project. That is not to say I have replaced them.... am just holding them a little bit closer until they are clearer to me. When I get there I may feel a bit more secure about bringing them out again.

Once again, issues of safety, security and trust are foregrounded as the participant admits that she is not yet ready to fully expose her thinking to scrutiny.

Boud and Walker point out that, "[c]ontext is perhaps the single most important influence on reflection and learning", and that the "broader social, political and cultural context influences every aspect of learning" $(1998,196-7)$. As CPL convenors, we have to be keenly aware of the multi-layered context in which we, and our participants, operate. Participants potentially have a great deal invested in both aligning themselves with the dominant values and practices they encounter in their immediate workplace, and in retaining the approach to learning which has served them well in the past. If we are to empathise and build trust with participants then sensitivity to the broader influences, expectations, conventions and demands that participants experience is required. While our earlier work has focussed on the portfolio itself and, to some degree, the "technical" and "humanistic" aspects of assessment, the emphasis on trust building comes from an awareness of the multifaceted learning culture in which both CPL convenors and course participants are immersed (James, 2014, 156-7).

It is perhaps not surprising, then, that CPL participants can find the demands of reflective practice challenging. Most striking in Fitzpatrick and Spiller's account is the first line in which the participant describes her shame at being "ambushed" by what feels like a straightforward task. The feeling of surprise at her lack of apparent competence is something that can also affect CPL convenors who assume that successful academics -and therefore successful learners- ought to be able to cope with the demands of the reflective portfolio. Maybe we should not be so surprised since the nature of reflective writing stands in stark contrast to the controlled, decisive and impersonal arguments that traditionally characterise academic writing. To reflect productively, CPL participants may need support and encouragement to "explore 'a state of perplexity, hesitation, doubt', 'inner discomforts', 'disorienting dilemmas', uncertainties, discrepancies and dissatisfactions" (Boud and Walker, 1998, 192). This distinction between academic and reflective writing is not just stylistic - it signifies a real difference in the type of learning involved. Trevitt has argued elsewhere that 'academic learning' and 'learning in academia' (i.e. to practice as an academic) are not the same thing: "Learning in an academic context, or 'academic learning', typically has been interpreted to mean 'book knowledge', or the development of knowledge and expertise within a discipline", while, "learning in academia'... implies learning while doing. It 
encompasses not only the process dimension of disciplinary inquiry, but also the increasingly important experiential learning associated with the practice-based knowledge that we amass 'on the job' in the workplace." (2008, 495). This distinction helps explain why some academics struggle with reflective portfolios, and how CPL convenors might fail to make explicit and explore with participants the differences involved. Such a realisation challenges our often taken-for-granted assumption that academics are expert learners readily able to understand and adapt to the demands of portfolio learning and writing. Rather, they have to expand how they understand learning, and CPL convenors CPL convenors have to both recognize this challenge and find ways to support participants in negotiating and surmounting it.

\begin{tabular}{|c|c|c|}
\hline $\begin{array}{c}\text { Continuing Professional } \\
\text { Learning }\end{array}$ & Feature & Academic learning \\
\hline Reflective portfolio & Assessment tool & $\begin{array}{c}\text { Essay/report/exam/Multiple } \\
\text { choice/thesis/viva }\end{array}$ \\
\hline $\begin{array}{l}\text { Early Career Academic (on } \\
\text { probation?) }\end{array}$ & Participant & Undergraduate/Masters/PhD \\
\hline $\begin{array}{l}\text { Explicitly both summative } \\
\text { (certification/qualification) } \\
\quad \text { and formative } \\
\text { (reflection/development). }\end{array}$ & $\begin{array}{c}\text { Purpose of assessment } \\
\text { (summative or formative) }\end{array}$ & $\begin{array}{l}\text { Summative or formative (feedback for } \\
\text { learning) - rarely both. Primary focus on } \\
\text { summative for measurement and testing } \\
\text { (selection, placement, certification, } \\
\text { qualification). }\end{array}$ \\
\hline $\begin{array}{l}\text { Learning in and of context, } \\
\text { and about self in context. }\end{array}$ & $\begin{array}{l}\text { Nature and focus of learning } \\
\text { being demanded }\end{array}$ & $\begin{array}{c}\text { Engagement with a defined disciplinary } \\
\text { curriculum }\end{array}$ \\
\hline $\begin{array}{l}\text { 'Free learning' (flexible within } \\
\text { agreed boundaries) }\end{array}$ & Structure & $\begin{array}{l}\text { Performing/demonstration of } \\
\text { disciplinary capability/knowledge } \\
\text { according to a proscribed curriculum }\end{array}$ \\
\hline $\begin{array}{l}\text { Continuing professional } \\
\text { learning (i.e. assessment as } \\
\text { snapshot of a point in an } \\
\text { ongoing journey) }\end{array}$ & Time frame & $\begin{array}{l}\text { Time-bounded curriculum (as courses) } \\
\text { (summative assessment as 'end-point' of } \\
\text { 'coming to know') }\end{array}$ \\
\hline $\begin{array}{l}\text { Signifiers of authenticity. } \\
\text { Assessors use professional } \\
\text { judgement within broad } \\
\text { criteria. }\end{array}$ & Criteria for assessment & $\begin{array}{l}\text { Accomplished and fluent in the } \\
\text { discipline. Rubrics and criteria are } \\
\text { defined to support objective judgement. }\end{array}$ \\
\hline $\begin{array}{l}\text { Semi-public learning and } \\
\text { assessment (related to } \\
\text { importance of context) }\end{array}$ & Privacy & $\begin{array}{c}\text { Anonymous/confidential summative } \\
\text { assessment }\end{array}$ \\
\hline $\begin{array}{l}\text { Professional body (e.g. HEA), } \\
\text { possibly aligned or } \\
\text { amalgamated with } \\
\text { institutional award (e.g. } \\
\text { postgraduate degrees) }\end{array}$ & Awarding body & $\begin{array}{l}\text { HE Institution (governed by national } \\
\text { standards eg via Quality Assurance } \\
\text { Agency in UK) }\end{array}$ \\
\hline
\end{tabular}

Table 1: Features of Continuing Professional Learning, its assessment and its context compared with similar features of academic learning.

In Table 1 we outline some of the differences between CPL and 'academic learning', and associated assessment. The features are generalised and exceptions to the broad characterisations outlined will be evident in particular institutions or courses. Furthermore, it could be argued that the features of CPL described in the leftmost column are idealistic - for instance, that we might aspire to assessment that is primarily focussed on reflection and development but that, in reality, is dominated by participants' focus on simply 'passing' and getting back to their 'real' work. The framework in Table 1 highlights indicative differences rather than being comprehensive ${ }^{\mathrm{ii}}$ and, as with all aspects of CPL, the context in which participants are working will determine how these differences are experienced. The intent is to identify some of the tensions between 'academic learning' and 'learning in academia' that participants may experience, and to underline the uncertainty that those tensions might prompt. Under such circumstances, where participants' expectations 
and prior experiences are challenged, a greater level of trust (in the course convenor and processes) is needed in order to have the confidence to abandon tried and tested approaches in favour of something new.

\section{The role of trust in learning-oriented assessment}

Recognition of the importance of trust in education can be traced back at least as far as Carl Rogers. Rogers suggests that the successful facilitator of learning must both express "realness or genuineness" $(1998,198)$, and recognise "the fear and hesitation of the student as she approaches a new problem" $(1998,199)$. Mutual empathy, trust and understanding allows a more productive relationship between student and tutor, where real teaching and learning (rather than transmission of information) can take place - "If I distrust the human being then I must cram her with information of my own choosing lest she go her own mistaken way. But if I trust the capacity of the human individual for developing her own potentiality, then I can provide her with many opportunities and permit her to choose her own way and her own direction in her learning" $(1998,203)$. Authentic engagement with CPL therefore requires that participants perceive the course convenor to be trustworthy if they are successfully to abandon some of their established and proven approaches to learning in favour of new and untried ones. The convenor therefore also has to be similarly authentic and "not only to 'walk the walk' and 'talk the talk', but to be able to be seen to do so" (Trevitt, 2008, 498). Likewise, trust in assessors is required too. Mantze Yorke points out that a judgemental approach to assessment (as opposed to a measurement approach) "makes overt the need for trust in the professional judgement of assessors" (2010, 269). Where the nature of what is being assessed is not conducive to measurement against explicit criteria and strict rubrics (but rather defined though "broad statements of expectations" (Yorke, 2010, 253), the professional judgement of the assessor must come into play - and that judgement must be trustworthy for participants to have faith in the assessment process. In our practice, a number of approaches have been taken in order to attempt to ensure that participants trust the assessors and the assessment processes. These endeavours are reported in several papers elsewhere, but have included: considerable efforts to make our assessment expectations explicit - for us, for participants and for other assessors (see Trevitt and Stocks, 2012, 252-3); an iterative approach to portfolio compilation which adopted a "participant-centred and practicebased stance, along with an action learning approach" (Trevitt et.al. 2014, 71); and involvement of academic colleagues in the assessment process so that participants can be reassured that their work is being judged by at least one assessor from a cognate discipline who therefore, to some degree, understands their disciplinary background.

A whole host of relationships characterise the broader context in which participants work where trust will impinge on participants' comfort with offering an honest account of their teaching in the portfolio. At the least, participants have to negotiate trust-based relationships with:

- $\quad$ The CPL course convenor (as well as course tutors and assessors who may not necessarily be the same people). In deciding how much trust and credibility to put into the course and its convenor, participants may consider, for instance, the convenor's reputation within the University (or that of the convenor's unit). Furthermore, the regulatory aspects of the tutor/assessor's role serve to reinforce institutional and/or professional values. The history of discipline and control associated with assessment means that "[m]ore than any other aspect of education, assessment embodies power relations between the institution and its students, with tutors as custodians of the institution's rules and practices" (Reynolds and Trehan 2000, 268). To the extent, then, that the convenor/tutor/assessor is perceived to be promoting or maintaining standards condoned by the institution, participants will not deviate from the norms that are advocated in their broader work context. On the other hand, it is possible that the values of the course convenor (and therefore the course) are at odds with the institution, and more in line with, say, the Higher Education Academy who accredit many of the UK's learning and teaching in Higher Education programmes. In this situation, a participant may have to balance the need or desire to pass the course with the potential for setting him/herself against some of the values of the institution and/or discipline in which s/he works;

- Colleagues in their own department, school or discipline with whom they are trying to establish credibility, and who may identify more with quality in research than in teaching. Stephen Brookfield has described the alienation experienced by newly reflective teachers as 'cultural suicide' whereby 
"critical learners...risk being excluded from the cultures that have defined and sustained them up to that point" (1994, 208);

- $\quad$ Peers undertaking CPL (often from other disciplines) with whom participants are expected to engage in open and frank discussions and related development activities (e.g. teaching observations, joint investigations, etc);

- $\quad$ Students, for whom credibility is less likely to lie in a lecturer's research expertise and more likely to be associated with his/her effectiveness as a teacher;

- The institution as a whole (i.e. exploring its values, traditions, expectations, processes, aspirations) and understanding where one's contribution 'fits in'. The institution is also subject to contemporary values and pressures being placed on HE to report and manage performance, and that increasingly now filters down to impact on academic work at the level of the individual (see below); and,

- The academic profession more broadly (as embodied by Professional Bodies, qualifications, expectations from Government, disciplinary expectations and traditional pedagogic approaches).

While more established academic staff may find it easier to negotiate these relationships,since they are likely to have greater status and power, early career academics must consider the longer term impact of their decisions. By asking participants to reflect via the portfolio and, in so doing, to make their private thoughts public, we ask them to take a potential risk.

Nowadays, participants have to negotiate this range of complex relationships in an environment in which trust has been increasingly replaced by the monitoring and measuring of academic performance: "[d]uring the last 25 years or so managerialism has become a substitute for trust" (Carless, 2009, 79). In contrast to most assessment tasks, the portfolio foregrounds incompleteness as participants describe their current position while also acknowledging further work to be pursued. In asking participants to admit that there is potential to improve 'performance', we ask them to expose an apparently 'imperfect performance' within a process of summative assessment that is all too often embedded in a prevailing climate of managerialism. In seeking an honest account, we ask participants to reveal their misconceptions, mistakes and failures that contributed to their (practice-based) learning. Such expectations run counter to a competitive regime in which people understandably are not disposed to acknowledge their 'failures'. Nevertheless, articulating such 'failures', misconceptions and partial understandings not only offers a more convincing account of learning, but is also crucial to the formative function of the portfolio since, "[f]or formative feedback to flourish it is necessary for students to reveal their own partial conceptions: in other words to invest trust in the teacher. Conversely, 'faking good' occurs when students present themselves as knowing more than they actually do, for fear that revealing their weaknesses may be used against them" (Carless, 2009, 82). While CPL participants are not 'students' in the same way that undergraduates are, the fear that exposing their weaknesses could undermine their credibility and their position is clearly very real.

How can we build participants' trust in the CPL convenors and the CPL process?

In order to be effective, "[t]he learning portfolio requires course-participants to be open, trusting and prepared to be vulnerable" (Klenowski et. al., 2006, 281). Furthermore, as Karm indicates, effective reflection requires a supportive environment where participants not only have time, space and the opportunity to understand how to reflect, but also have the encouragement and co-operation of colleagues and peers: "[d]eeper reflection processes are enhanced by circumstances such as time and place, supporters, a critical friend or colleague, an emotionally supportive environment, the necessary knowledge base, and metacognitive skills" $(2010,206)$. Not all participants will find the conditions necessary for constructive reflection in their day-to-day work context. CPL convenors, then, "need to create a micro-context within which the kinds of reflection acceptable to learners and consistent with the values of learners and teachers can occur and which does not reproduce those aspects of the dominant context which impose barriers to learning" (Boud and Walker, 1998, 202). Below, we begin to identify how course convenors might go about building the trust levels required in order for participants to feel able to offer an authentically reflective account for summative assessment.

To "filter the negative influences of the larger context" CPL convenors not only have to focus on the assessment process, but also have to actively manage certain aspects of the learning environment (Boud and Walker, 1998, 199). Ground rules may need to be established so that participants are clear about, for instance, 
the level of confidentiality they might expect and the amount of support that they can count on from the convenor, tutor(s) and other participants. Conversely, CPL convenors may also need to accept that particularly junior or newer participants may not be willing to fully expose themselves, their thoughts and their practice to (semi-)public scrutiny. Not only do we ask participants to trust us with their mistakes and 'failures' but we also ask them to critique their context and potentially to set themselves against the established approaches which operate around them. Participants may be understandably unwilling to risk challenging the practices and values dominant in their discipline or institution in a semi-public form, and CPL convenors have to accept this. We have discussed elsewhere the fact that anonymous portfolio assessment is rarely achieved since the nature of reflection itself at least partially exposes the author -as s/he inevitably discusses the context in which s/he works- and, in fact, may not even be desirable. In the case of portfolios, the views expressed cannot be separated from the person who expresses them, and participants as well as CPL convenors have to be comfortable with this.

Klenowski et. al. suggest that one potential way to build trust between convenors (and tutors ${ }^{\mathrm{iii}}$ ) and participants, is to challenge the power dynamic which exists between tutor and learner. While we may think that a CPL tutor working with academic staff enjoys a more equitable relationship than a discipline tutor might enjoy with his/her students, we argue that the CPL tutor is actually in a more complex position. The CPL tutor all too often is seen as the 'expert' in learning and teaching, even while s/he may not fully understand the nuances and challenges of teaching a particular discipline. This places the CPL tutor in a challenging position where trust is difficult to sustain. However, if both parties see themselves -and, perhaps more importantly, each other- as co-learners, each with insight into areas that the other may not fully understand, there is clearly potential for exploring together and critiquing different approaches to teaching and learning. However, establishing both parties as co-learners is not easily done. Klenowski et. al. argue that, CPL convenors and tutors "should not ask course participants to be open if they are not prepared to take the same risks themselves" (2006, 281). They should be willing to expose their strengths and areas for development, thereby opening up "the opportunity for the development of a real community of learners" within a CPL programme (Klenowski et. al., 2006, 281). Nevertheless, "this relationship challenges the traditional, hierarchical status between tutor and student" (Klenowski et. al., 2006, 281), and such a shift in the perceived role of the tutors clearly impacts on other aspects of the learning environment. Therefore, even while we might work to challenge the traditional relationship between tutor and participant, we need to be alert that such a challenge may prompt further anxiety in participants.

We have argued elsewhere that it is essential to have a clear understanding of the criteria for assessing reflective portfolios. While this may seem obvious, our experience of uncovering and articulating nuances in 'signifiers of authenticity' for the benefit of ourselves, other assessors and our participants illustrates some of the challenges involved (see Trevitt and Stocks 2011, 7-10, Table 1). Where assessment procedures are perceived to be opaque or covert, it is not surprising that participants would have little trust in the process or in the assessor. Developing an awareness of how exactly 'authenticity' plays out in the judgement process is a necessary first step to being transparent for the benefit of others. Explicit 'signifiers of authenticity' can instil greater confidence (and trust) in the overall assessment approach and use of a reflective portfolio.

\section{Closing comment}

In our previous work, we focussed on the CPL programme itself and explored how the values and demands of the portfolio process might be negotiated by convenors and communicated to participants. Here, we have explored how the broader context in which such CPL programmes are situated can impact on participants' experience of learning about academic practice. We have also further explored the complexity of assessing 'learning in academia' via the reflective portfolio, although much more remains to be said on this topic. For instance, most portfolios are compiled and assessed once, offering a 'snapshot' of learning at a given point. However, as van der Vleuten, Schuwirth, Scheele, Driessen and Hodges suggest, portfolios "tend to work best if they perform a very central function...in monitoring longitudinal competency development" $(2010,8)$. There may, then, be potential for the continued use of portfolios in ongoing and longer term professional learning. The difficulty of assessing everyday practice which is not amenable to what Yorke defines as 'realist' approaches to assessment (see 2010, 253) could also benefit from further consideration as we continue to promote greater expertise (and therefore trustworthiness) in working with and judging reflective portfolios. 
In this paper we have explored the role played by trust for participants engaging with CPL opportunities. We suggest that issues of trust lie at the heart of many academics' struggles with the requirements of the reflective portfolio. Success in 'academic learning' does not necessarily lead to successful 'learning in academia' - making this clearer to participants may prevent them from feeling 'ambushed' by the portfolio process. Facilitating the shift from a type of learning in which CPL participants are well rehearsed to one which can be unexpectedly alien requires empathy on the part of convenors along with insight into pressures arises from the broader managerialist context of modern academic work. Trust, and processes of trust-building in the CPL process and portfolios as a reflective tool are key. By working to establish trust, CPL convenors are more likely to foster portfolios based on authentic pedagogic thinking rather than performativity. By making explicit (to themselves, to senior management, to course participants, to tutor and assessor colleagues) the way that trust and trust-building underpins the process of authentic portfolio development and assessment, CPL convenors are engaged in a vital leadership role, enhancing assessment literacies, increasing transparency in award decision making, and hence playing their small part in building confidence in the integrity of higher education and its institutions. This is a crucial message for the contemporary academic development community, embedded as it is in a context increasingly 'deeply affected by accountability, quality audits and associated distrust' (Carless, 2009, 86) but one in which opportunities to shape substantial CPL initiatives may now also be enhanced (HLGMHE, 2013).

\section{References}

Boud, David (1990) Assessment and the promotion of academic values. Studies in Higher Education 15: 1, 101-111.

Boud, David (2000) Sustainable assessment: Rethinking assessment for the learning society. Studies in Continuing Education 22: 2, 151-167.

Boud, David and David Walker (1998) Promoting reflection in professional courses: the challenge of context. Studies in Higher Education, 23: 2, 191-206.

Brookfield, Stephen (1994) Tales from the dark side: A phenomenography of adult critical reflection. International Journal of Lifelong Education, 13: 3, 203-216.

Carless, David (2009) Trust, distrust and their impact on assessment reform. Assessment and Evaluation in Higher Education, 34: 1, 79-89.

FitzPatrick, Mary Anne and Dorothy Spiller (2010) The teaching portfolio: institutional imperative or teacher's personal journey? Higher Education Research and Development, 29: 2, 167-178.

Hatton, N and D. Smith (1995) Reflection in teacher education: Towards definition and implementation. Teaching and Teacher Education, 11:1, 33-49.

High Level Group on the Modernisation of Higher Education (HLGMHE) (June 2013) Report to the European Commission on Improving the quality of teaching and learning in Europe's higher education institutions. (84). Available at: http:// ec.europa. eu / education /library/ reports /modernisation_en.pdf

James, David (2014) Investigating the curriculum through assessment practice in higher education: the value of a 'learning cultures' approach. Higher Education, 67, 155-169.

Karm, Mari (2010) Reflection tasks in pedagogical training courses. International Journal for Academic Development, 15: 3, 203-214.

Kember, David, Jan McKay, Kit Sinclair and Frances Kam Yuet Wong (2008) A four-category scheme for coding and assessing the level of reflection in written work. Assessment and Evaluation in Higher Education, 33: 4, 369-379.

Kharouf, Hunsi, Harjit Sekhon and Sanjit Kumar Roy (2014) The components of trustworthiness for higher education: a transnational perspective. Studies in Higher Education. DOI:10.1080/03075079.2014.881352

Kvale, Steinar (2007) Contradictions of Assessment for learning in institutions of higher learning in David Boud and Nancy Falchikov (ed.s). Rethinking Assessment in Higher Education: Learning for the longer term. London: Routledge.

Nicol, David and Macfarlane-Dick, Debra (2006) Formative assessment and self-regulated learning: a model and seven principles of good practice. Studies in Higher Education, 31: 2, 199-218.

Reynolds, Michael and Kiran Trehan (2000) Assessment: a critical perspective. Studies in Higher Education, 25: 3, 267-278.

Rogers, Carl (1998) The interpersonal relationship in the facilitation of learning in Taking issue: debates in guidance and counselling in learning by Megan Crawford, Richard Edwards, Lesley Kydd (ed.s). London: Routledge. 
Sadler, Royce (1989) Formative assessment and the design of instructional systems. Instructional Science, 18, 119-144.

Trevitt, Chris (2008) Learning in academia is more than academic learning: action research in academic practice for and with medical academics. Educational Action Research, 16: 4, 495-515.

Trevitt, Chris (2005) Universities Learning to Learn? Inventing Flexible (E)Learning through First- and SecondOrder Action Research. Educational Action Research, 13: 1, 57-83.

Trevitt, Chris and Claire Stocks (2011) Signifying authenticity in academic practice: a framework for better understanding and harnessing portfolio assessment. Assessment and Evaluation in Higher Education 37: 2, 245-257..

Trevitt, Chris, Claire Stocks and Kathleen Quinlan (2012) Teaching portfolios for learning and assessment in academic practice: negotiating tradition, current tensions and future promise. International Journal for Academic Development, 17: 2, 163-175.

Trevitt, Chris, Anne McDuff and Aliya Steed (2014) [e]portfolios for learning and as evidence of achievement: Scoping the academic practice development agenda ahead. Internet and Higher Education, 20, 69-78.

Van der Vleuten, C.P.M, L.W.T Schuwirth, F. Scheele, E.W. Driessen and B. Hodges (2010) The assessment of professional competence: building blocks for theory development. Best Practice and Research Clinical Obstetrics and Gynaecology, doi:10.1016/j.bpobgyn.2010.04.001.

Yorke, Mantze (2010) Summative assessment: dealing with the measurement fallacy. Studies in Higher Education, 36: 3, 251-273.

Young, Pat and Zoë Irving (2005) Integrity of practice in lecturers' accounts of teaching decisions. Studies in Higher Education, 30: 4, 459-472.

For a fuller explanation of what we mean by 'authentic' in this context, see Trevitt and Stocks (2012) Signifying authenticity in academic practice: a framework for better understanding and harnessing portfolio assessment, Assessment and Evaluation in Higher Education, 37:2, 248-9. It is also possible to see a connection between our work in that paper and David Kember's writing on coding and assessing levels of reflection. Some of his criteria for 'critical reflection' might also apply to what we consider to be 'authentic' accounts - in particular we would see evidence that a candidate has "conduct[ed] a critical review of presuppositions from conscious and unconscious prior learning and their consequences" leading to "a transformation of perspective" as a good indicator that the portfolio is truly representative of the learner's journey (Kember et. al., 2008, 374)

ii In compiling this table, we found it useful to consider the list of questions proposed by David James $(2014,165)$. He suggests that his questions might help course teams who are designing new assessment practices to understand the learning culture in which they function, but they have also been useful in helping us to understand the disjunction between the broader learning culture within which our participants work and the demands we place on them as they learn about academic practice.

iii As suggested earlier, the course convenor (who has overall responsibility for the course and how it is assessed) may be the same as the course tutor (ie the person who delivers the course), but they might also be different people.

Dr. Claire Stocks is the Humanities Faculty Researcher Development Officer at the University of Manchester.

Dr. Chris Trevitt is an Educational design consultant at The Australian National University College of Law

\section{Corresponding Author:}

Dr. Claire Stocks

Room G.004 Crawford House

University of Manchester

Manchester

M13 9PL

claire.stocks@manchester.ac.uk

01613061116 